\title{
Incidence of motor neurone disease in the Northern Region
}

\author{
NAWAB QIZILBASH AND DAVID BATES \\ From the Royal Victoria Infirmary, Newcastle-upon-Tyne
}

SUMMARY The incidence of motor neurone disease in the Northern Region was studied for the year 1981 by means of hospital activity analysis records and questionnaire. The crude incidence rate was ${ }^{0}$ $2 \cdot 2$ per 100000 . This was not significantly different from the rate determined by using death certification. The age standardised incidence ratio for the region was 163 using the 1976 population and deaths from motor neurone disease in England and Wales as the reference. The female to male ratio was 1: 1.8 and the average age of diagnosis was 63 years. No meaningful intraregional variation was observed. Thus mortality appears to reflect incidence fairly accurately.

Motor neurone disease is a progressive illness with anterior horn cell and pyramidal tract involvement usually leading to death within five years. Annual incidence rates are approximately 1.0 per 100000 , and many studies have used death rates as an easier substitute for incidence because, with the short survival time, mortality rates should approach incidence rates.

A recent study gave figures that would result in an annual crude mortality rate of 1.6 per 100000 for the area covered by the Northern Regional Health Authority. ${ }^{1}$ Experience suggested that this figure was an underestimate, and, furthermore, intraregional variations were thought to exist with a higher incidence in the west of the region. The present study was therefore carried out to clarify the picture and to test the validity of using mortality as a proxy for incidence, by measuring as far as possible the actual incidence from admission and diagnosis in hospital. Motor neurone disease is a condition which usually results in hospital admission at some stage, and this method of identifying patients should consequently be accurate and complete.

\section{Method}

Motor neurone disease has been classified as codes 3352,3358 , and 3359 under the ninth revision of the International Classification of Diseases introduced in 1979. Hospital activity analysis records were used to search for discharges in the year 1981 with such a diagnosis made apparently for the first time during the year.
Questionnaires were sent to the relevant consultants $ᄋ$ in order to confirm the clinical diagnosis of motor neurone disease, establish that the diagnosis was fir 3 made in 1981, check for duplication of patients, ang exclude cases of spinal muscular atrophy and other $\frac{O}{5}$ non-motor neurone disease causes entered under the codes.

Deaths from motor neurone disease were obtained from the Office of Population Censuses and Surveys. Cases were analysed by age, sex and district, and Student's $t$ test was used.

\section{Results}

The response rate, with exhaustive follow-up, was 99\%: of 176 cases identified, only two records were untraceable. Of the traced 174 cases coded as 3352 , 3358 , and 3359,78 cases were confirmed as having had $\overparen{\curvearrowright}$ motor neurone disease first diagnosed in 1981. The ? remaining 96 cases were either cases of motor neurone $\frac{5}{3}$ disease diagnosed before 1981 , or other conditions, $\stackrel{3}{\circ}$ such as cerebrovascular disease causing progressive $ᄋ$ bulbar palsy. Of the 78 cases, seven were duplicates and three patients were from outside the region.

The crude incidence rate for the Northern Region $>$ was $2 \cdot 2$ per 100000 . Adjusted for age and sex to the population and deaths from motor neurone disease in $N$ England and Wales in 1976, this resulted in a standardised incidence ratio of 163 . This is obtained $\tilde{N}$ by reporting the observed cases as a percentage of the $\mathrm{N}$ expected deaths. The crude mortality rate was 2.0 per 100000 ; there were 61 deaths in the region for 1981.0 The difference between the two rates was not $\frac{D}{\Phi}$ 
statistically significant. The female to male ratio was $1: 1 \cdot 8$, being greater for ages 65 and above $(1: 4 \cdot 2$ and less for ages below $65(1: 1 \cdot 2)$. The mean age of diagnosis was 63 years; for men 65 years and for women 61 years this difference was not significant (table 1).

The age and sex specific incidence ratios according to District Health Authority areas in the region are shown in table 2. Although no significant differences are demonstrable for females, there are statistically significant inter-district standardised incidence ratio differences for men. For example, the standardised incidence ratio for West Cumberland is significantly higher than for Durham or South West Durham.

\section{Discussion}

There is said to be an annual incidence rate of motor neurone disease of approximately 1.0 per 100000 of the population. It has been noted that this figure is reasonably constant throughout the world. ${ }^{2}$ There are some exceptions, such as the isolated foci in Guam ${ }^{3}$ and the Kii peninsula of Japan. ${ }^{4} A$ recent report using death certification noted significant regional variations within England and Wales. ${ }^{1}$

Using clinical hospital diagnosis of motor neurone disease for the Northern Region, there was no

Table 1 Age and sex distribution of the 68 cases

\begin{tabular}{lcc}
\hline Age $(y r)$ & Male & Female \\
\hline $25-34$ & 0 & 1 \\
$35-44$ & 0 & 1 \\
$45-54$ & 7 & 2 \\
$55-64$ & 12 & 12 \\
$65-74$ & 18 & 8 \\
$75-84$ & 5 & 1 \\
$85+$ & 1 & 0 \\
\hline
\end{tabular}

Table 2 Standardised incidence ratios for motor neurone disease by district within the Northern Region $(S I R$ for the Northern Region $=100)$

\begin{tabular}{lrc}
\hline District & Males & Females \\
\hline Hartlepool & 0 & 0 \\
North Tees & 247 & 105 \\
South Tees & 91 & 116 \\
East Cumbria & 321 & 320 \\
West Cumbria & 527 & 226 \\
South Cumbria & 64 & 0 \\
N W Durham & 125 & 158 \\
S W Durham & 76 & 0 \\
Durham & 52 & 68 \\
Darlington & 93 & 0 \\
Northumberland & 227 & 49 \\
Gateshead & 168 & 68 \\
Newcastle & 124 & 144 \\
North Tyneside & 117 & 0 \\
South Tyneside & 142 & 265 \\
Sunderland & 266 & 328 \\
\hline
\end{tabular}

statistical difference between the rate assessed in this manner and that using death certification ( $2 \cdot 2$ per 100000 versus 2.0 per 100000 respectively). This lack of statistical difference persisted even after removing South Cumbria, which is also served by the North West Regional Health Authority, and would therefore reduce the incidence for the Northern Region from the analysis. This sort of error is likely to creep into any study based on hospital analysis within a single region. Figures based on death certification from the Office of Population Census and Surveys will not harbour this error. In this study, $4 \%$ of the entire cases identified were from outside the Northern Region. Death certification appears to be an acceptable means of assessing incidence. It is certainly much easier than tracing all hospital records. The high diagnostic accuracy in death certification of motor neurone disease does seem to occur in different areas. The error from failure to record motor neurone disease on either parts one or two of the death certificate when the diagnosis has been made clinically is of the order of $5 \% .^{15}$ This study, assuming no significant change in incidence over a five year period, showed a difference of $10 \%$ between deaths and clinical cases of motor neurone disease diagnosed in 1981. Assuming the reported increase of around $33 \%$ in the mortality rate from motor neurone disease for England and Wales over the 18 years from 1958 to 1961 and 1977 to $1979^{1}$ continues, and also reflects trends in the Northern region, then the figure of $10 \%$ would be further reduced. This feature is reassuring as it indicates that there has been no dramatic increase in incidence in the past three to five years, assuming that survival of the disease nationally is similarly reflected in the Northern Region.

Atypical cases are unlikely to introduce significant errors between the number of cases diagnosed clinically and certified because such cases of motor neurone disease not diagnosed clinically would not be subsequently diagnosed post mortem. Likewise obvious cases having been missed clinically would also not be so certified, and death from another neurological disease erroneously attributed to motor neurone disease would raise figures but not necessarily mortality figures, because a necropsy may then reveal the true cause of the illness.

The mean age of diagnosis of 63 years and the female to male ratio of $1: 1.8$ accord with other recent studies. ${ }^{15}$

There was a "statistically significant" intra regional variation, but this result should be treated with extreme scepticism. Though an a priori hypothesis existed, because the result was significant only when compared with two districts with the lowest standardised incidence ratios, it is unlikely to be real. The numbers are also too small for much assurance to 
be placed in the result. Though it is interesting in affecting only men, occupation has been implicated in its aetiology. Unfortunately, none of these factors can be easily invoked here.

This study has reassuringly validated the use of mortality as an adequate surrogate measure of incidence for this condition.

We thank Mr A McNay for statistical support.

\section{References}

${ }^{1}$ Buckley J, Warlow C, Smith P, et al. Motor neurone disease in England and Wales, 1959-1979. J Neurol Neurosurg Psychiat 1983; 46: 197-205.

${ }^{2}$ Kurland LT, Epidemiological investigations of amyotophic laternal sclerosis. III. A genetic interpretation of incidence and geographic distribution. Proc Mayo Clin 1957; 32: 449-62.
${ }^{3}$ Chen K, Brody JA, Kurland LT. Patterns of neurologic diseases on Guam: I. Epidemiological aspects. Arch Neurol 1968; 19: 573-8.

${ }^{4}$ Yase Y. VII. Neurologic diseases in the Western Pacific Islands, with a report on the focus of amyotrophic lateral sclerosis found in the Kii Peninsula, Japan. Am J Trop Med Hyg. 1970; 19: 155-66.

5 Juergens SM, et al. ALS in Rochester, Minnesota 19251977. Neurology 1980; 30: 463-70.

${ }^{6}$ Rosen AD. Amyotrophic lateral sclerosis: Clinical features and prognosis. Arch Neurol 1978; 35; 638-42.

${ }^{7}$ Mulder DN, Howard FM Jr. Patient resistance and prognosis in amyotropic lateral sclerosis. Proc Mayo Clin 1976; 51: 537-41.

${ }^{8}$ Campbell AMG, Williams ER, Barltrop D. Motor neurone disease and exposure to lead. J Neurol Neurosurg Psychiat. 1970; 33: 877-85.

${ }^{9}$ Kantarjian AD, A syndrome clinically resembling amyotrophic lateral sclerosis following chronic mercurialism. Neurology (Minneap) 1961; 11: 639-44.

${ }^{10}$ Kurtze JF, Beebe GW. Epidemiology of amyotrophic lateral sclerosis. I. A case-control comparison based on ALs deaths. Neurology (Minneap) 1980; 30: 453-62.

11 Alpers BJ, Farmer RA. Role of repeated trauma by pneumatic drill in production of amyotrophic lateral sclerosis. Arch Neurol 1949; 62: 178-82.

12 Breland AE, Currier RD. Multiple sclerosis and amytrophic lateral sclerosis in Mississippi. Neurology (Minneap) 1967; 17: 1011-6.
International Conference on "Detection methods for DNA-damaging agents in man: Applications in cancer epidemiology and prevention"

\section{Espoo, Helsinki, Finland 2-4 September 1987}

This conference, sponsored jointly by the International Agency for Research on Cancer (IARC) and the Institute of Occupational Health, Helsinki, will promote critical appraisal of methods for detecting DNA-damaging agents and their immediate effects in humans, their application in research into the causes of human cancer, and their use in monitoring the exposure of humans to known carcinogens. A particular objective of the conference is to foster, through multidisciplinary discussions, the use of these methods in future research in cancer epidemiology. Measurement methods discussed will include analysis of human tissues and body fluids for adducts of carcinogens with DNA, RNA and protein, and analyses for carcinogen-modified nucleobases, thioethers, indicator nitrosamines, and mutagenic metabolites.

One session on measurement of the effects of alkylating agents will be dedicated to the honour of Professor L. Ehrenberg's scientific contributions to this and related subjects.

For further information and abstract/registration $D$ forms, please contact: K. Hemminki, Institute of Occupational Health, Topeliuksenkatu 41 a A, 00250 Helsinki, Finland 